

\begin{abstract}
This article explores an aspect of the cultural modulation of recovery in psychosis. It begins with the idea that recovery hinges on the ability of subjects to relate to their distressing experiences in ways that expand rather than diminish agency. Based on fieldwork in the Dakhla oasis of Egypt and subsequent analysis, it is argued that interpretations of psychosis as spirit possession offer a broader range of intentionality than biomedical interpretations and therefore broader possibilities of relating to psychotic states. Modes of relating to spirits may take active or passive forms, the former consistent with the recovery goal of symptom control. Factors constitutive of the active, agency-expanding mode of relating include: the nature of spirits; the values and beliefs of the subject; the broader cultural/religious discourses which may make it either more or less likely for the subject to achieve the desired state of control over symptoms.
\end{abstract}

Keywords: Islam; North Africa; schizophrenia; Jinn; recovery 


\section{From Powerlessness to Control: Psychosis, spirit possession \& recovery in the Western desert of Egypt}

\section{A. Rashed}

\section{Introduction}

Commencing in 1966, a number of international studies of schizophrenia were conducted by the World Health Organisation (WHO). One of the most important findings to have emerged from these studies was that the outcome of schizophrenia is better in 'developing' than in 'developed' research centres. ${ }^{1}$ This finding was attributed to the "pervasive influence of a powerful factor which can be referred to as 'culture"' (Jablensky et al. 1992:89). The WHO studies have been criticised on various grounds. ${ }^{2}$ One criticism concerned the way 'culture' was employed to interpret the results. Anthropological critics concurred that cultural factors influence course and outcome of disorder (e.g. Jenkins 1991) but noted, disapprovingly, that 'culture' was used as "synonym for unexplained variance" (Edgerton and Cohen 1994:228) and as a "mock-elegant way of referring to 'there' as opposed to 'here"' (Hopper 2004:65). 'Culture' was equated with thinly-defined variables such as 'work' or 'marriage', which were adopted as explanations for better outcomes. Critics argued that what determines if marriage will be protective is the "adaptive capacity of the established relationship, the kinship capital and practical/emotional support invested by the families" (2004:78); that is, the meaning and consequences of marriage (and not marriage per se). Overall, the issue of contention seemed to be how differences in outcome may be best explained, but the construal of outcome itself, the model of recovery which underpins the outcome measures on which the findings were based, was not explicitly addressed.

Models of recovery "fall along a continuum from more objectively to more subjectively based indicators of outcome" (Jenkins et al. 2005:212). As evident from the scales employed, the WHO studies were concerned with clinical recovery, which consists in the fulfilment of 'objective' measures: symptom remission, resumption of function such as work or school, independent living, and social engagements. The Recovery literature draws a distinction between clinical recovery, which is based on the medical model and requires cure from illness, and personal recovery. The latter, according to Anthony's (1994) pioneering article, is a concept that arises from the consumer/survivor movement. It refers to "a deeply personal, unique process of changing one's attitudes, values, feelings, goals, skills, and/or roles ... a way of living a satisfying, hopeful, and contributing life even with limitations caused by illness" (1994:527). Personal recovery does not require cure in the medical sense, rather it emphasises that one can lead a fulfilling life alongside and in spite of symptoms of illness (cf. Roberts and Wolfson 2004). Recovery, as described by advocates and service-users, is an ongoing process or a journey rather than a definite outcome (Lieberman et al.

\footnotetext{
${ }^{1}$ See Hopper et al. 2007, Hopper 2004 and Jablensky et al. 1992.

2 One criticism was that applying 'Western' categories of psychopathology in contexts where they lack coherence constituted a category fallacy: mistaking reliability for validity (Kleinman 1987). In practice, this was resolved by noting awareness of the cultural-historical origins of the category of schizophrenia while stressing that "operationally defined, [it] provides the methodological consistency necessary for comparative analysis" (Jenkins 1991:421).
} 
2008). Reviews of the voluminous Recovery literature by Leamy and colleagues (2011), Schrank and Slade (2007), and Bonney and Stickley (2008) identified the following elements of the recovery process: Hope; motivation to change; connectedness through participation and access to the community; formation of meaningful relationships; redefinition of a positive sense of identity that incorporates experiences of illness; overcoming stigma; empowerment through taking responsibility and control over one's life; developing meaning and purpose through social roles, goals, and spirituality.

A central element of recovery is the idea of gaining 'control'. When the term 'control' appears in the literature, more often than not it refers to control over, or taking charge of, one's life (e.g. Farkas 2007:69; Lieberman et al. 2008:492). This is connected to empowerment and to reclaiming power and responsibility over decision-making and definition of goals. This meaning of 'control' has been rightly criticised as promoting an individualistic, medicalised view of distress whereby it is the person that must change rather than - or in addition to - social and political conditions implicated in distress and disability (Harper and Speed 2012). Further, the cross-cultural transferability of this concept of recovery has been questioned by Mike Slade, an early promoter of the concept (Slade et. al 2014). The language of 'empowerment', 'control', and 'responsiblity' betrays a culturally specific set of values and conceptions of the person where autonomy, boundedness and mastery over self are paramount. It is clear that these values and conceptions are by no means universally shared. That is not surprising given that the concept of personal recovery was first expressed in North America by a civil-rights inspired mental health consumer/survivor movement. However, the concept is not necessarily irredeemably lost for the purpose of cross-cultural examination.

The concept of personal recovery can be fruitfully employed if we understand recovery in a more basic sense than afforded by the complex and arguably culturally-specific notions of 'empowerment' and 'responsiblity'. This is to be found in an alternative understanding of the meaning of achieving control over symptoms which turns on a basic conceptualisation of agency. In the context of health discussions, a symptom is a mental state made salient on various grounds, most commonly by virtue of being distressing and/or disabling in whatever way this manifests. For example, for some individuals, experiences of voices or of passivity of action may disrupt the person's ability to get on with their ordinary daily activities. A symptom can thus undermine/constrain a basic sense of agency defined as a fundamental, socio-culturally mediated capacity to act in the world (cf. Ahearn 2001: 112). To achieve control over a symptom is to restore this capacity to act. In this sense recovery requires of subjects to relate/respond to psychotic states in ways that allow them to get on with their lives; i.e. to restore agency. Rufus May, a clinical psychologist and recovery advocate, makes a similar point when he argues that recovery requires of individuals to manage voices so that the experiences "do not hold them back from getting on with their lives". This is premised on the idea that "it is not the voices or unusual beliefs that are the problem, rather the person's relationship with these experiences that will determine how distressing they are" (emphasis added). ${ }^{3}$

This article seeks to explore the idea of 'control over symptoms' by looking at how subjects related to their experiences of psychosis in an Egyptian oasis. In that community, spirits (jinn) feature prominently in the experience of psychotic phenomena. A question here is how can subjects gain, or fail to gain, control over psychotic states when the culprit, or source, is a spirit, i.e. a being with agency? 'Relating' to a biomedical entity is different from 'relating' to an agentic entity bound up with the subject in complex religious and moral discourses. The connection between spirit-based frameworks and outcome in psychosis has been previously noted. In the context of the WHO studies, it was hypothesised that "idioms of illness attribution that exempt the self" (Hopper 2004:63), such as spirit possession, may contribute to better outcomes through promoting favourable social responses. Al-Issa (1995) suggested that certain interpretations of psychotic states afford the subject a greater degree of control and may promote favourable

\footnotetext{
${ }^{3}$ Understanding Psychotic Experience And Working Towards Recovery. Available at: http://rufusmay.com/index.php?option=com content\&task=view\&id=30\&Itemid=33
} 
outcomes. However, what is needed is not a general statement to the effect that spirits help or hinder but an ethnographic exploration of people's attempts, through spirit-based frameworks, to control psychotic states. This coheres with Hopper's (2004) comments, cited above, that identifying work or marriage (or spirits) as protective factors is not enough, what is needed is an account of how these 'factors' can be helpful (and when they might not be) by looking at the details of individuals' lives in cultural contexts. Central to this account is the idea that recovery requires of subjects to respond to psychotic states in ways that expand rather than diminish agency. Agency, understood as the capacity to act in the world on a day to day, hour by hour basis, can be disrupted by psychotic states, for instance through distraction and fear. Achieving control requires that subjects are able to relate and respond to such states in ways that allow them to get on with their lives, i.e. in ways that expand rather than diminish agency.

\section{Ehtnographic Context \& Methodology}

Fieldwork on which this article is based was conducted between May 2009 and April 2010 at the Dakhla oasis in the Western desert of Egypt. ${ }^{4}$ The Ministry of Health set up a public hospital in Mūt, the urban centre of the oasis, in addition to a number of basic, primary care units in the many villages. Absent from the oasis, indeed from the whole parent governorate of the New-Valley, are mental health services. On the rare and desperate occasion when a family need to consult a psychiatrist, they must travel to Asyut $(600 \mathrm{~km})$ or Cairo $(1000 \mathrm{~km})$. The dearth of psychiatrists is compensated for by an abundance of Qur'anic healers (mu'alij bil-Qur'an). Qur'anic healing in Dakhla proceeds through incantation (ruqya) of specific verses from the Qur'an. This form of healing has its roots in preIslamic 'magico-religious' remedies including incantation to the many gods in the Arabian Peninsula and which the Prophet Muhammad had adopted and purified of illegitimate polytheistic elements (Al-Najjar 1995). Today, Qur'anic healing is practiced widely in Egypt (Coker 2009) and other parts of the Islamic world (e.g. Al-Rowais et. al 2010; Deuraseh 2009).

People consult Qur'anic healers for a variety of problems: social such as marital discord and spinsterhood; chronic, untreatable pains; individuals who are behaving strangely, roaming the village, isolating or talking to themselves, frequently crying or aggressive. In all these cases, the shared understanding that tends to bind healers, patients and their families is that affliction and misfortune have arisen due to the presence of spirit (jinn) influence or possession brought about inadvertently or through magic (se'hr). In Dakhla, se'hr is understood to consist in an agreement between a sa'her (magician) and a jinni to the effect that the former engages in extreme acts of desecration and apostasy (kufr) to secure the latter's help and obedience. The magician may then employ these obedient jinn for various purposes: to assist clients in securing revenge, harming and disadvantaging others, or recovering Pharaonic relics buried in the oasis' sands. The jinn employed towards such harm are understood to be unbelievers who have abandoned God and engage in evil (sharr) actions. These are actions performed with the explicit intention to bring harm and misfortune upon others. The main task before a Qur'anic healer is to utilise the blessings (baraka) and power of the word of God, the Qur'an, to dispel or contain the evil that has entered in the form of the jinni and hence to resolve the problems - mental or physical symptoms, social disadvantage, etc. - that have resulted from this.

Magicians - perceived to exist widely in the oasis - are often seen to be the engineers of misfortune. Despite this, and although magic in light of Islamic revivalist currents is strictly prohibited, people seek powerful magicians to help with problems seen to exceed healers' capacities. Healers seek to distance themselves from magic, and portray

\footnotetext{
${ }^{4}$ Ethical approval for this study was obtained from University College London Research Ethics Committee (Project ID: 1521/001). Confidentiality and anonymity is upheld with regards to all informants: no actual names are used and data that can aid identification has been omitted or changed.
} 
themselves as engaged in a battle with magicians and evil jinn to uphold God's ideal order. The order of things as conceived by God includes humans and jinn existing within His domain with the purpose of worshipping Him: interactions among them should not be part of an ideal conception of that order. Separating the temporarily tangled natures of human and jinni is an attempt to return God's order to its ideal state. Qur'anic healers see their vocation in those terms. For the public, however, a thin line separates healers from magicians and no one can be completely trusted. Especially mistrusted are healers who demand a fee for consultation, the argument being that if they are motivated by material concerns, and not solely by serving God, then they might also dabble in magic as a guaranteed way of spreading more harm and receiving more patients and money. This backdrop, expanded upon as required in what follows, will contextualise the case studies presented.

Fieldwork was based on participant observation in everyday contexts and healing settings in which I observed and learnt about Qur'anic healing. The two case studies included in this article fulfilled the DSM-IV criteria for Schizophrenia and both individuals experienced symptoms during the period of research. Engagement with Kamal and Fayza continued throughout the research, and life- and clinical-histories were obtained through initial biographical and clinical interviews and subsequent informal interviews. I also interviewed family members to ascertain their understanding of the problem and its evolution over time. In addition, semi-structured interviews were carried out with eleven healers and fifty-six members of the community to ascertain their views on possession, mental illness, healing, magic, and the spirit-world. The following case-histories represent the subjects' point of view and what they considered to be relevant aetiological factors for their experiences and problems.

\section{Psychosis in the Dakhla Oasis}

\section{Kamal}

Kamal is a 20 year old man, the second oldest of four children. At the age of 17 he was beaten by a school teacher in front of the morning assembly. Humiliated, he vowed never to return and failed to attend his final exams which were only two months away. Kamal was angered at his father for not confronting the teacher and getting him his "rights back". His father was concerned that Kamal was ruining his future and tried to persuade him to return to school, frequently beating him. Kamal suffered with insomnia and agitation which he attributed to the teacher's attack. He began to run away from home, and spent much of his time roaming the village. His father did not want to leave him in this state and frequently forced him to return and locked him in. Eventually, Kamal persuaded his father to allow him to stay at a shed owned by the family in the semi-deserted part of town and which was now only used to keep livestock. He stayed in a bare room and only left for food when the village was quieter. During this period and through a number of delusional interpretations Kamal developed the belief that his real parents were the president and the first-lady (Egyptian ex-president Hosni Mubarak). For instance, Kamal, who considered himself a farmer, took Mubarak's rhetoric concerning the "needs of the simple peasant and the underprivileged" as referring to him; it was his father's way of showing he cared.

Kamal returned home and resumed roaming the streets. He began to declare in town that his father was Mubarak, a declaration that was, understandably, ridiculed by others. This resulted in confrontations, and his father had to intervene on several occasions to bring him home. Once, he stopped a ministerial motorcade that was visiting the oasis and demanded to be taken to his father Mubarak, an act that landed him in a police cell for two days. Faced with ongoing and increasingly serious problems, Abbas chained his son to prevent him leaving the house, and sometimes his younger sister helped him escape. It became apparent in the family that they needed to seek help. Kamal sought a number of healers in town; this is how he described the encounters: 
You go to a sheikh and he recites Qur'an. He writes things on paper, recites some more. You know the system; amulets, holy water [...] But I only accepted sheikh AbdelAziz. He recited and then said "you are mamsūs [touched], ${ }^{5}$ you were walking somewhere and got touched, you stepped over something [a jinni]". That second I knew it, it must have been when I fell in the rice-fields that night. How did he know it was a touch? He is a blessed man. He recited the Qur'an and knew; he looked at my fingers, I was trembling and he said "there is something here". And he gave me some water to wash with and drink. Did this help? Just calmed me [...]

Kamal embraced sheikh AbdelAziz's view yet the cause of his insomnia and agitation remained the teacher's beating. A few months later the diagnosis of possession became more relevant:

I was watching a film at Ali's coffee-house, a scary movie. It finished late and I was walking home scared and wanted to get back quick. I saw Hamada [also Kamal's first name] driving by and asked him to take me home. I got in the car and then I heard someone calling behind us: "Hamada!" I looked back and there was a man standing, I could only see half his body [...] The driver is also called Hamada and I thought he was calling him. But he didn't respond, and he told me "don’t look back". And the voice was still coming, "Hamada!" closer then farther away [...] He dropped me home and I was scared. When I entered the house I found that my family's faces had changed [...] I didn't know if they were my family.

Who was this man calling your name? Now I know it's him, the one with me. From that day this man appeared to me everywhere; I could feel him and hear him. I couldn't live or go to the mosque. And the sheikh had already told me I was touched in the rice-fields, and I thought what touched me there must have come with me here.

And what do you do when you feel him with you?

In the beginning I would run away. I would be heading to the mosque at dawn and would feel him by side; I get scared and run home. At times I asked him what he wanted from me; I would shout at him but he wouldn't answer. But then I learnt not to talk to him after sheikh AbdelAziz told me he was a Muslim jinni and wouldn't hurt me. He walks with me and I leave him as he is walking with me; I feel him by my side, and sometimes I hear him, like wind, blowing in my ear [...] I let him be, if he wants to be with me I let him, but I don't hurt him and he doesn't hurt me.

Kamal disclosed his experiences to his mother and she arranged a trip to Asyut to consult a more powerful healer. The healer gave him an amulet and when he placed it against his chest he felt suffocated and threw it away. He suspected the sheikh was a magician who presented himself as a healer and couldn't trust him. Weeks later Abbas took his son to Asyut again, this time for a first psychiatric consultation. He was diagnosed with Paranoid Schizophrenia, given Electro Convulsive Therapy and discharged on antipsychotic treatment. He accepted that he had a mental illness caused by the beating he sustained to his head at the hands of the teacher. ${ }^{6}$ This illness accounted only for symptoms of insomnia and agitation. With regards to his experience of the spirit:

\footnotetext{
${ }^{5}$ Spirit-interference can be in the form of a 'touch' which is milder than 'possession', although the two terms are used interchangeably.

${ }^{6}$ A common theory of mental illness is the 'Drop of Blood Theory'. Following a sudden shock, humiliation or beating to the head, blood forms a "drop" which settles on the nerves, stimulating and damaging them and producing the problematic behaviours. The blood can be "dissolved" through ECT, and the disruptive behaviours may cease.
} 
No, the jinni is something else, nothing to do with the illness. This is a labsa [possession incident] that came with the illness; they are separate. They are two: marad nafsi [mental illness] and labs [possession]. The possession came from the rice-fields, what touched me there came with me here. I have both possession and illness in my head, and I needed the sheikh and the doctor.

Kamal had accomplished a breakdown of his problems. For the illness he used medication on rare nights as a sleeping aid. On the other hand, the jinni continued to disrupt his life through its presence and calling his name. To avoid confrontations in town, he spent his mornings in bed and, as night fell, at Ali's coffee-house. On one such night Kamal told me about a square black-head, like a statue's, that his mother had recently found in his room. The family identified it as a magician's hex and it was Kamal who was intended with the harm. His brother arranged for a healer from a neighbouring village to deal with the hex. Kamal suspected that the man was a magician who lied to make people think we was a sheikh:

How did you know that?

I couldn't tolerate the smell of the incense. He wrote talasem [talismans] on paper and burnt it. The ashes from the incense fell on the ground and formed a square shape under my feet. It was the exact shape of the head we had found. Then I understood [...] And I told him “I don't want you, leave the house!" I didn't feel comfortable. He wanted to make me more unwell so he could take our money.

Kamal's family, who attended the session, also felt uncomfortable in the man's presence. Following this encounter, and a subsequent one with a magician who slaughtered a rabbit and wrote talismans with its blood, Kamal no longer wished to see any healers.

The sheikhs can make you more unwell. The Qur'an is good but you don't know what they write on paper [talismans]. They could heal you but could also hurt you.

How do you treat possession without healers?

God is the one making me unwell [possessed], but the sheikh can become unwell and then I get more unwell, and then we will just sit there at a loss, who will help us? Then you get a second sheikh but he could fall unwell too; it's only the Qur'an that will save us. Healers take money from you, they have forgotten God.

Concurrent with the development of this position, during 2009, Kamal began to pray regularly at the mosque and always stayed behind to listen to religious sermons:

I learn from the Imams not to listen to magicians and so-called healers. They will take your money and claim to heal you; the healer is God. I hear many religious lessons and I don't believe the things magicians write, the things they do with blood, instead of taking out of you [a jinni] they may introduce into you. The healer himself may be possessed and transfers it to you. The Qur'an heals, you don't need a mediator for that; I listen to the Quran and pray and fast.

His family supported his increased religious observance. His grandmother proudly told me that Kamal now fasted every Monday and Thursday (a sunna). Kamal's new religious attitude seemed to help him cope with the spirit as these excerpts indicate: 
I am sure now God is with me. I read the Qur'an so I don't get hurt or unwell.

I still hear him and feel him with me, but I know what to do. I am not afraid of him. He can't hurt me. When

he is there I pray, I invoke God's name, I recite and listen to Qur'an.

Sometimes when I am working I feel he is there and I hear him; I pray to myself, I read the fati'ha. With all the prayer and the time I spend in the mosque God stands by me. When something distracts me from prayer I get unwell.

Kamal had also become more active and I could see him around town assisting shop-keepers. Returning to the village after a brief visit to Cairo I noticed further progression in his religiosity. He had let his beard grow freely in the traditional sunni style and shaved his moustache. He said he had listened to sermons extolling the virtues of the beard and decided to go ahead. He also swapped his usual mosque for another known to be popular with the "Beards", the name given by locals to those who adopt a more austere version of Islam and whose untrimmed beard stands for their ideological position. Some people encouraged him to keep the beard while others, including his mother, advised against it. They were worried he would be noticed by local police who monitored beard-wearing men as part of Mubarak's government's strategy to counter 'terrorism'. Towards the beginning of 2010 he had shaved it. Returning from Asyut after a work errand, he was stopped at a check-point and questioned about a recent spate of violence among the Coptic-Christian/Muslim population in a nearby village. He was let go after his companion explained that Kamal was unwell and could not be involved in such activity. On returning home he shaved his beard, "it is safer this way". He continued to attend the mosque and align his life with the Prophet's through dietary habits, sunna prayers, fasting, and recalling God in his actions.

\section{Discussion: from powerlessness to control}

I want to highlight Kamal's developing relationship with the spirit he experienced. The idea of spirit possession became relevant for Kamal following the perceptual disturbances he experienced returning home late from the coffee-house. His elaboration was consistent with cultural beliefs regarding jinn, for instance that they can appear to people and influence their perceptions. Kamal embraced the idea that this was the spirit that touched him in the fields. He remained distressed by his experiences; he couldn't "live or go to the mosque" and would drop what he was doing and run home in panic. He was powerless towards a range of phenomena that dominated him. He had not yet devised a strategy to deal with the spirit and was unable to get on with his life.

The second stage was avoidance; after learning from the healer that the spirit was Muslim and would not hurt him, he began to ignore it: "If he wants to be with me I let him, but I don't hurt him and he doesn't hurt me." Avoidance, as a strategy, implies some sort of relation with the entity being avoided. In Kamal's case this was possible after that entity was endowed with further defining characteristics such that he could respond to it.

Further encounters with healers cemented the suspicion that many of those who claim to be so were magicians who might hurt him. While this belief might have in his case a delusional foundation, it is in fact widely entertained in the community, as indicated earlier. Mistrust of healers in the context of a developing religiosity convinced him that what he needed was prayer and the Qur'an. The Qur'an can heal even if you read it yourself or play it on a cassette. This idea is gaining more popularity in Dakhla and it is likely that Kamal had heard it at one of the religious sermons he attended. Self-healing is associated with the rejection of dubious (un-Islamic) healing practices or the need for mediation between God and a pious person.

By splitting his problems, Kamal left the "mental illness" for the doctors, occasionally taking the medication, while dealing with the "possession" became a personal struggle and a matter of faith. This was the third stage, resistance, where he began to take an active stance in responding to the spirit, utilising, in his developed religiosity, 
the power of the Qur'an and prayer as a direct means of countering its presence. The Qur'an now became a "weapon" in his struggle. It was during this period that he was able to overpower the spirit and reengage with society; resistance thus gave way to control. He thus regained a sense of control in spite of the spirit that still appeared to him. And he was able to do this through various coping strategies that enabled him to respond to the spirit there and then as he experienced it.

The idea that a person can resist a spirit without mediation from healers reflects an active response to affliction that does not rely on the authority or knowledge of the experts. Kamal's rejection of healers and magicians under the pre-text that you can't tell who is who is only part of the explanation for this stance. It is underpinned by an ethos of purism; purifying Islam of suspect accretions and practices, such as all-powerful healers, to a direct relationship with God through the Qur'an and prayer. I will shortly return to this in more detail. For now I want to point out that the features of Kamal's response which underpinned his ability to achieve control were that his response was active, personal, and religiously/morally framed. Another brief case study will provide a contrast and bring out further features of this response.

\section{Fayza}

Fayza is a 38 year old unmarried woman who lives with her brother and his family. Her problems began in the mid-90s following two months of self-imposed isolation. This was in response to a betrayal at the hands of a neighbour who had gone to "make money" in Kuwait and who had promised to marry her upon his return. The families exchanged gifts and Fayza built her hopes, only for the news to arrive two years later that he had married another girl. Fayza, like the majority of women of her generation, had never been to school. She spent her teenage years with her mother learning about domestic matters. Throughout the late-80s and early-90s she had had several marriage proposals but was not content with any of them. The "betrayal" was painful and socially problematic; having "wasted" two years of her life waiting she was now, at twenty-seven, approaching the liminal age where questions will be asked why she hadn't married all these years.

During those initial two months Fayza rarely left the house and was frequently crying and screaming in her room. She began to fear that her brother's wife, her relatives and neighbours wanted to hurt her. On the few occasions when she left the house, she was apprehensive towards those she encountered in the village and her behaviour was unpredictable. She also described a felt presence, a "man" accompanying her, who spoke to her telling her she would never get married and would remain a spinster. She was terrified by these experiences:

I was scared of him. He walks with me and I said to myself I will stay in my room. I wanted to visit my cousins but I couldn't; he shouts at me and confuses me, and I run back and lock myself in.

Hussein took his sister to a healer who diagnosed the presence of a jinni. When he started the incantation she felt something wrap around her chest and her body was shaking. Hussein and Fayza accepted the sheikh's diagnosis. She believed that this spirit had been directed at her through magic arranged by her cousin, who according to Fayza was a jealous, vengeful woman. Fayza never confronted her cousin, and began frequenting healers and magicians behind her brother's back: she was intent on undoing the magic to free herself of the spirit. Her brother did not agree with this; he knew his cousin well and could not believe she would do this. He was also concerned that Fayza was selling her jewellery to fund her quest. Eventually, in order to stop her wasting more money and prevent her roaming the village at night (inappropriate for a woman and a sign of madness) he began to restrict her movements.

Recently Hussein took his sister to Asyut to see a psychiatrist. She was diagnosed with Paranoid Schizophrenia, suffered side-effects on treatment, and subsequently only rarely took medication. On one of my meetings with her, in the presence of her brother, she re-iterated that she still believed she was subject to magic and was disappointed at her social situation. 
MAR: So what is the main problem now?

FAYZA: Marriage. Do we have anything else but marriage?

HUSSEIN: Of course, what else will make her happy, what is the goal of life without marriage and children? Spinsterhood is a mosiba [disaster].

MAR: Do you have other problems?

FAYZA: God wants me to die $[\ldots]$

HUSSEIN: [Quickly interrupting] Tell him how you spend your time.

When I met Fayza on her own she was less hesitant than in her brother's presence. I explored with her what she meant when she said God wanted her to die:

A few years ago God began to appear to me. It happens to this day. Now I want to die, God tells me to die. God appears to me, now he is here with us, spread throughout but hasn't appeared. What does he look like? I can't tell you, if I do he will burn or do something to me. How do you know it's God? When I pray and say 'Oh God, make me well, bring back my health' he appears to me and says 'Die!'

Does God talk to you?

Things I don't understand, but he says 'die!' Maybe I should die and end this. What do you do when this happens? What can I do? I stay in my bed and think about dying. You can't escape God. Could it be anything else? Could it trick me? The jinni saying its God? He appears, I see fire in my eyes, my body burns. In the beginning it was a jinni, the sheikh told me, but now I don't know [...] God is merciful and compassionate; why would he do this to you? He wants me to die; all people die in the end don't they?

What does your brother say?

That I have a mental illness; that's what the doctors told him. He doesn't want me to talk about this.

Have you sought any help?

I went to the sheikhs. My cousin went to El-Senussi [magician]; she didn't want me to get married, she was jealous. Do you think there is still magic on you? Yes.

\section{Discussion: the failure to achieve control}

Like Kamal, Fayza understood her experiences in a spirit idiom. Unlike Kamal, Fayza was unable to achieve a modicum of control; i.e. she was not able to relate or respond to the spirit in ways that expanded agency. What is striking about their responses was the way in which Fayza was focused on the idea that she is subject to magic, and will only get better if she can undo it. Kamal, on the other hand, rejected healers and magicians. Fayza did not perceive herself able to take personal, direct action to deal with the spirit, and relegated this task to the experts, the healers and magicians, whom she visited regularly. But Fayza was subject to constraints arising from gender; restrictions on her movement were because she was "ill" and a woman. Together with financial considerations, these constraints 
prevented her from following through her quest to undo the magic. Compared to Kamal, she was not able to personally relate to the spirit in a way that overpowered it whether through avoidance or resistance for instance. The transformation of the spirit into an uncharacteristically vengeful god signals the final stage of the failure of achieving control, and there is no longer anything she can do apart from contemplate killing herself. In fact at that point she is no longer sure of the identity of the entity possessing her, let alone be able to relate to it. Fayza's overall response can be described as passive and led by the experts rather than her own personal resources and coping strategies.

\section{Modes of relating to spirits}

The cases of Kamal and Fazya evince different modes of relating to spirits, what can be referred to, respectively, as the active and the passive. These two modes do not exhaust all the possible ways of relating to spirits, but as they emerge in the cases of Kamal and Fazya they offer a helpful contrast. Active and passive, in this context, are to be understood as pertaining to the features of the response or attitude towards the spirit or the psychotic states. An active response is one in which the subject develops personal coping strategies to deal directly with psychotic experiences. Kamal, for instance, found reciting the Qur'an and repeating invocations helpful in preventing, to a certain extent, what he perceived as a spirit from curtailing his agency. Further, these were activities which were available to him, requiring no expert input, and in this sense afforded him a further measure of control over his situation. A passive response, by contrast, is one in which the development of personal coping strategies is secondary to submitting to the knowledge and authority of the experts who become responsible for healing. Fayza's response can be characterised in those terms. To offer an example from clinical practice, the distinction here would be between a person hearing voices and responding to this by rushing to the accident and emergency department and asking the doctor to do something about it, and another person hearing voices and employing a distraction technique to cope with the voices such that he can get on with his day: the latter may be described as evincing an active response.

Given the notion of gaining control over symptoms as central to recovery, the active mode of relating reflects a greater degree of personal agency than the second more passive mode, and therefore affords more of a possibility for achieving such control. From the perspective of the recovery process, gaining control is a personal accomplishment; it is something the subject/patient must be directly involved in, rather than a passive observer of. In this sense, it is the first mode of relating that is consistent with the recovery process.

These two modes of relating to spirits suggest that we cannot, as stated in the introduction, make a general statement to the effect that spirits help or hinder. Clearly, this is dependent on many factors including, crucially, the mode of relating to the illness, in this case the spirit. In what follows I would like to consider how these modes arose by stepping back from the specifics of the cases and looking at changes to the conceptualisation of spirits and possession in Islam and the research community. How did spirit-based frameworks come to permit such contrasting modes of relating to affliction? Especially, how did active, person-led approaches arise? By addressing these questions we can have a better understanding of factors that may promote or hinder the recovery process and which extend beyond the confines of the doctor/healer - patient/subject relationship.

\section{The Islamisaton of Spirit Possession Discourse}

The two modes of relating to spirits, the active and the passive, arise from two construals of spirit possession, what can be called, respectively, the Islamic and the traditional. Essentially, the Islamisation of traditional spirit possession discourse involves changes to three interconnected elements: (1) The nature of spirits; (2) the extent and means by which humans are permitted to interact with spirits; and (3) the role of religion in this.

\section{The nature of the spirits}

The spirit world in Dakhla, as in contemporary Cairo (El-Kholy 2004) and the Nile-delta (Morsy 1993) is dominated by the jinn, creatures of fire mentioned in the Qur'an. This contrasts with other contexts, such as the South- 
Eastern coast of Africa, where spirits reflect different histories and personages (e.g. Lambek 1988; Sharp 1994). In fact, in Egypt this has not always been the case where in earlier times the jinn existed alongside spirits of dead relatives (Winkler 1933/2009), regional Ethiopian and Arab spirits (Al-Gohary 1977), and beasts such as the ghoul (Padwick 1924). Popular descriptions of the jinn ${ }^{7}$ in Dakhla and Egypt exceed that available in the Qur'an and are a syncretism of Babylonian, Egyptian, Jewish and pre-Islamic Arabian influences ( $c f$. Sengers 2003:Ch.2). The central contribution of the Qur'an was that it located spirits within a moral framework: like us they worship God, possess agency, and are subject to trial and punishment.

The recession of other non-human beings in favour of the current prevalent view of spirits is a relatively recent phenomenon. This, perhaps, could be understood as another manifestation of the widely recognised Islamic revivalism that has swept across large swathes of the Muslim world (Gellner 1992), and which seeks a strict interpretation of the text and a purification of Islamic practice and belief from what is deemed 'traditional' and parasitic upon the faith. This influence extends to defining the permitted spirits. For instance, Giles (1995) in a study of spirit possession along the Swahili coast, observed the decline of animalistic and pagan spirits and a move towards austere, music-free ceremonies in the context of increasing Arab and orthodox Islamic influences in the region. McIntosh (2004) noted among the Giriama of coastal Kenya the development of a taxonomic distinction between high-status Muslim (jinn) spirits and low-status Giriama spirits in the context of Swahili Muslim hegemony. The dominance of the spirit world in Egypt and elsewhere by a particular view of the jinn brings a number of implications.

\section{The extent and means by which humans are permitted to interact with spirits}

The jinn, unlike spirits of royalty and dead ancestors, are not there to be appeased or sought. According to a strictly Islamic view, humans are the unfortunate recipients of spirit-interference and possession is an affliction to be undone. In Dakhla, people are strongly prohibited by healers and Imams from liaising with or seeking spirits, a view also found among the Muslim Tuareg (Rasmussen 1995). ${ }^{8}$ Others have pointed out the resistance to Islamic hegemony: Masquelier (2002) observed among the Mawri of the Niger that the gradual Islamisation of Mawri communities is met with the continued presence of a small core of 'pagan' spirits followers and servants. The orthodox Islamic prohibition on spirit-human commerce is to be contrasted with other societies where senior spirits could provide the host with an elevated social status as healer (Lambek 1988), where certain spirits must be instated to develop a medium-ship and avoid the harm that could accrue from resistance (Sharp 1994), and where spirits are helpful entities sought for health, money and advice (Placido 2001).

A formal Islamic doctrine would not allow such practices since they contradict a fundamental principle of the faith: Tawhid. Any appeal to or flirtation with a power other than God is a violation of the absolute oneness and power of God. This is precisely what magicians have to violate in order to enlist the services of the most powerful jinn to conduct their business including exorcisms. A move towards a formal Islam eschews medium-ship and appeasement and limits the interaction with spirits to unconditional rejection. Qur'anic healing, in which the healer forces a possessing spirit to speak through the host and negotiates its exit from the body, is not always seen to violate

${ }^{7}$ According to popular views, jinn are gendered, can be Muslim, Christian, unbelievers, smart or ignorant. They marry and procreate amongst themselves and with humans. They generally live underground, but are known to inhabit impure and deserted places, open fields and water-ways. They can travel instantly across large distances and can appear in animal and human form

8 This formal attitude towards spirits tends to be portrayed as a male-specific discourse. Boddy (1994) writes: "In Islamic societies where traffic with spirits is formally discouraged, men's public religiosity may require them to handle possession via exorcism instead of mollification" (1994:415). In Dakhla, both men and women publicly rejected traffic with spirits, while privately some, mostly women, admitted making offerings to spirits 
the principle of non-appeasement if the healer is firm with the spirit and not yielding to its demands. However, negotiation is also seen as unnecessary, and bordering on appeasement, when healer and subject have at their disposal the power of the Qur'an.

\section{The role of religion}

Another implication of the Islamisation of spirit possession is its fundamental embeddedness in a moral/religious framework. Whatever the proximal causes of possession a person only becomes possessed if rendered vulnerable through weakness of faith. Consequently, strengthening one's faith is necessary both to protect against, and to rid oneself of, spirit-interference. Resisting the spirit becomes a personal act of faith, and the resources to deal with such an encounter are those which are available for all, being what a good Muslim is expected to do: prayer and reciting the Qur'an. This may enable the individual to resist the possessing spirit, since he or she already has the required resources. And, importantly, it is possible to do so through an unmediated relationship with God. The idea of using the Qur'an for self-healing is gaining more popularity in Egypt, partly through publications with titles like 'Healing Yourself with Al-Ruqya Al-Shar'iyya' sold for symbolic prices at bus stops, and the proliferation of cassette sermons and websites devoted to similar topics ( $c f$. Hirschkind 2009). These constitute a resource of 'self-help' and a democratisation of Qur'an healing; no longer limited to the esoteric practices of the experts and available to everyone.

The Islamic discourse on spirit possession, in Kamal's case, underpins the active mode of relating to spirits identified in his response. In that mode the subject is directly involved in the healing process and owns the resources for coping. And this mode, as also indicated, is consistent with the recovery process which emphasises the development of personal coping skills and strategies rather than passively relying on the interventions of the experts.

Finally, the Islamisation of spirit possession is not complete. Shadows of spirits' origins and modes of relating to them have persisted despite Islamic revivalism. These can be seen in the continued presence of magic which is an agreement between a magician and a jinni to the effect that the former engages in extreme acts of desecration to secure the latter's help and obedience. It can also be seen in zar ceremonies which include sacrificial and ritual appeasement of spirits carried out by zar specialists (see El-Kholy 2004; Morsy 1978). From a strictly Islamic point of view, appeasement of and negotiation with spirits is not condoned. To the extent that such practices emphasise expertise and submission to the healers over the development of personal coping skills and strategies, they may be described as encouraging a passive attitude and relation towards the spirits. This does not imply that ritual healing and exorcism cannot be beneficial for dealing with dysphoric states and dissonant thoughts: research suggests that such rituals have psychotherapeutic potential, for instance through the cathartic and culturally sanctioned release of emotion and repatterning of conflict (Bourguignon 1979), or by promoting insightful reflection on healthy dispositions of selfhood (Boddy 1988). Notwithstanding such benefits, if the concern is with achieving a degree of control over psychotic phenomena - in the sense of control defined in this article, then an active, engaged, personal attitude and relation towards the perceived sources of affliction, the spirits, is necessary

\section{Conclusive Remarks}

What are the implications of the preceding case studies and analysis to the discussion of the recovery process started in the introduction? This article started by asking how subjects can gain, or fail to gain, control over psychotic states. A theoretical approach that can shed some light on this question is the well known framework of the illness narratives (Kleinman 1988; Good 1994). This framework starts with the view that narrative is the ground of identity, providing a fundamental orientating function (cf. Crossley 2000; Phillips 2003). Narrative provides existential, moral,

\footnotetext{
${ }^{9}$ Ruqya is incantation using verses from the Qur'an. The qualifying adjective, shar'iyya (legitimate), differentiates religiously approved from forbidden ruqya such as employed by magicians.
} 
and practical anchorage in the present through positing a relatively continuous experiencing and acting self arising in the past and continuing into the future. The disruption of self-narrative by the experiences of psychosis (and illness more generally) can be disorientating and confusing, disinvesting the subject of an important sense of continuity and agency. Illness narratives, in this context, refer to subjects' attempts to re-narrate their life, to "provide coherence to the confusion and chaos generated by illness" (Mattingly 1998:107), contributing to - and not merely reflecting - "the experience of symptoms and suffering" (Kleinman 1988:49). This framework emphasises the importance of seeking narrative coherence and continuity where both have been disrupted by illness or by unusual experiences. But we need to go further if we are to understand in a more immediate sense how subjects are able to relate to their condition in ways that expand rather than diminish agency. Put differently, self-narratives may be coherent and stable yet constraining rather than enabling. We must ask then: what does control over psychotic states entail when the culprit is perceived to be a spirit as in spirit possession?

Spirits are understood to have human-like traits and agency and, as such, they are perceived to act under human-like reasons and it becomes possible to relate to them on that basis. Control over symptoms, from this perspective, rests on the subject's capacity to develop an empowering relationship towards the entity/agent they experience. A relationship implies that the entity I am relating to possesses intentionality. This intentionality is often projected. For instance, one can have a relationship with an animal or a machine, usually through a certain degree of anthropomorphisation whereby the animal's or machine's behaviour is interpreted in light of human desires and reasons. One can also have a relationship, albeit more metaphorical, with an illness, expressed, for example, in terms of emotive language such as fighting and winning the battle with cancer or illness in general, as if the illness is an aggressive adversary that must not be allowed to prevail.

Anthropomorphisation is an important approach by which humans relate to and control inanimate and nonhuman elements of the environment ( $c f$. Jackson 2005). Ascribing intentional states to the perceived sources of affliction creates the potential for relating to such sources and for responding to non-human entities with a range of typically inter-personal human responses such as resistance or avoidance. And this, as indicated above, applies both to biomedical and spiritual construals of affliction. In what sense then, as raised in the introduction, is 'relating' to a biomedical entity different from 'relating' to a spirit? The answer lies in the breadth of intentionality that can be ascribed and which is much wider with spirit than biomedical construals. A wider range of intentionality provides a broader range of possible ways of relating to and of potential control over the entity in question. For example, as we have seen with Kamal, after learning from the sheikh that the spirit possessing him was Muslim, he no longer believed it would hurt him. He was less terrified and was able to avoid it. Spirits, as opposed to biomedical mechanisms, possess a multitude of human-like traits that allow assumptions about behaviour to be made.

The word 'potential' in the previous paragraph suggests that not all ways of relating lead to control; Kamal and Fazya illustrate this point. One can be in a dominating relationship which diminishes rather than expands agency. The distinction between active and passive modes of relating to spirits highlights that the recovery goal of achieving control over symptoms requires that subjects expand their agency in relation to distressing and disabling phenomena through taking a direct and active role in defining their relationship with the perceived source of their affliction. Taking a passive attitude and leaving one's problems for the experts to handle is inconsistent with the personal work required for the expansion of agency. This is because what is at stake is the ability to respond to potentially disruptive psychotic states in ways that allow the subject to get on with ordinary daily activities and not be dominated by such states. The response will therefore necessarily have to be available to the subject right there and then, emerging from the personal relationship they have been able to adopt towards the perceived source of their affliction: the spirit. In Kamal's case expansion of agency was possible due to the way he appropriated a particular cultural discourse: the Islamisation of spirit possession and healing. This discourse provided for him the possibility of adopting an active, person-led 
response by which he achieved a modicum of control. It was also a discourse that was highly regarded in the community. Fayza, on the other hand, partly due to general gender-based restrictions on movement, had a diminished chance of encountering Islamist discourses on spirit possession, which Kamal was able to access through the freedom to attend sermons and develop his views.

We can now return to the concern raised at the beginning of this article: do spirit-based frameworks aid recovery in psychosis? As stated in the introduction, what is needed to address this question is not a general statement to the effect that spirits help or hinder, but an ethnographically grounded exploration of attempts to manage psychotic states through such frameworks. Such an exploration, as conducted in this article, suggests that spirits can aid recovery if the subject is able to take an active, person-led stance consistent with the expansion of agency required for achieving control over symptoms. A number of factors impact on this stance: the features of the spirits; the presence of cultural discourses that allow the possibility of taking personal action to resist the spirits; and the values and beliefs of the subject. Helpful cultural discourses are by no means limited to religious ones: the issue is not just the specific nature of the discourse, but whether or not the subject is able to draw from it the means for an active, person-led response.

The focus in this article on the potentially protective affordances of spirit possession frameworks is not, customarily, how spirit possession is approached in the anthropological literature. Attempts to explain possession trance as illness (e.g. Castillo 1994) or in terms of its sociological function (e.g. Lewis 1971), gave way to interpretive accounts concerned not so much with explaining or rationalising spirit possession but with understanding and interpreting its personal and social meanings (e.g. Boddy 1989; Lambek 1989; Crapanzano 1980). ${ }^{10}$ Particularly influential has been Crapanzano's (1977) formulation of possession as an idiom or metaphor through which individuals can articulate a range of experiences and problems. While this is undoubtedly a valuable perspective, this article adopted less an interpretive and more a pragmatic stance: the interest lay not in what people are expressing or communicating through the possession idiom or, more generally, on what possession 'means', but, rather, on what they are able to do with it in terms of managing and coping with disruptive and distressing states. Here, spirit possession is considered much like a personal tool rather than an interpretive conundrum. This approach to spirit possession, particularly for medical and psychiatric anthropology, can be helpful as it foregrounds and increases understanding of the various and subtle ways in which cultural frameworks can be employed to cope with suffering and illness.

Finally, from a clinical point of view, encouraging patients to anthropomorphise psychosis through spirit- or agent-based frameworks is a proposition that should not be ignored. Clinical psychiatry tends to insist on biomedical interpretations of illness, and the WHO, in its efforts to fight stigma, promotes similar views in educational projects in developing countries (WHO 2002). However, as Hopper had noted, "second thoughts might be given to "educational" campaigns that seek to substitute "scientific" models for local idioms of distress - especially when the science of beliefs is in such a primitive stage of development" (Hopper 1991:316). If the goal is to relate to symptoms in ways that promote recovery, then agent-based frameworks - while they cannot guarantee control - at least provide a wider breadth of intentionality than biomedical construals, and therefore a broader range of possible ways of relating to and of potential control over symptoms. In addition, it is worth remembering that the phenomenology of psychosis, by its nature, promotes an agent-based view - it is usually someone who is talking or controlling one's thoughts - and clinicians are familiar with the difficulty in shifting this view to a biomedical one. On those two points it seems prudent to work with agent-based frameworks, and to assist patients develop an active, person-led response to affliction in the service of recovery.

\footnotetext{
10 More recently, Emma Cohen (2007) advanced a research programme which seeks to rehabilitate explanation in the study of spirit possession. According to her, what demands explanation is the "persistence and spread of [possession] concepts" cross-culturally $(2007,15)$.
} 


\section{References}

Ahearn, L. (2001) Language and Agency. Annual Review of Anthropology. 30:109-137.

Al-Gohary, M. (1977) ‘Elm al-folklore wal mo’taqadat al-sha’beyya. Cairo: Madbouly Press

Al-Issa, I. (1995). The illusion of reality or the reality of illusion: Hallucinations and culture. British journal of psychiatry 166:368-373.

Al-Najjar, M. (1995). Al-Tib Al-Nabawi Bayn Al-Teb Al-‘elmi wal Teb Al-Sha’bi. Al-Funun Al Sha’bia 46:30-55.

Al-Rowais, N., E. Al-Faris, A. Mohammad, M. Al-Rubkan, \& H. Abdulghani (2010). Traditional Healers in Riyadh Region. The Journal of Alternative and Complementary Medicine 16(2):199-204.

Anthony, W. (1994). Recovery from Mental Illness. In Readings in Psychiatric Rehabilitation. W. Anthony and LeRoy Spaniol, eds. Pp.521-538. Boston: Boston University Press.

Boddy, J. (1988). Spirits and Selves in Northern Sudan: The Cultural Therapeutics of Possession and Trance. American Ethnologist 15(1):4-27.

Boddy, J. (1989). Wombs and Alien Spirits. Wisconsin: The University of Wisconsin Press.

Boddy, J. (1994). Spirit Possession Revisited: Beyond Instrumentality. Annual Review of Anthropology 23:407-434

Bonney, S. \& T. Stickley (2008). Recovery and mental health: a review of the British Literature. Journal of Psychiatric and Mental Health Nursing 15:140-153

Bourguignon, E. (1979). Psychological Anthropology. New York: Holt, Rinehart and Winston.

Castillo, R. (1994). Spirit Possession in South Asia, Dissociation or Hysteria? Part 1: Theoretical Background. Culture, Medicine and Psychiatry 18:1-21.

Cohen, E. (2007). The Mind Possessed: The Cognition of Spirit Possession in an Afro-Brazilian Religious Tradition. Oxford: Oxford University Press.

Coker, E. (2009). Claiming the Public Soul: Representations of Qur'anic Healing and Psychiatry in the Egyptian Print Media. Transcultural Psychiatry 46(4):672-694.

Crapanzano, V. (1977). Introduction. In Case Studies in Spirit Possession. V. Crapanzano and V. Garrison, eds. Pp. 1-40. London: John Wiley and Sons.

Crapanzano, V. (1980). Tuhami: Portrait of a Moroccan. Chicago: University of Chicago Press.

Crapanzano, V. (2000). Introducing Narrative Psychology: Self, Trauma and the Construction of Meaning. Buckingham, UK: Open University Press.

Deuraseh, N. (2009). Using the Verses of the Holy Qur'an as Ruqyah (Incantation): The Perception of Malay-Muslim Society in Kelantan and Terengganu on Ruqyah as an Alternative way of Healing in Malaysia. European Journal of Social Sciences 9(3):448-456.

Edgerton, R. \& A. Cohen (1994). Culture and schizophrenia: the DOSMD challenge. British journal of psychiatry 164:222-231.

El-Kholy, H. (2004). A Discourse of Resistance, Spirit Possession among Women of Low-income Cairo. In Health and Identity in Egypt. H. Sholkamy and F. Ghannam, eds. Pp. 21-41. Cairo: AUC Press. 
Farkas, M. (2007). The vision of recovery today: what it is and what it means for services. World Psychiatry 6:68-74.

Gellner, E. (1992). Postmodernism, Reason, and Religion. London: Routledge.

Giles, L. (1995). Sociocultural Change and Spirit Possession on the Swahili Coast of East Africa. Anthropological Quarterly 68(2):89-106.

Good, B. (1994). Medicine, Rationality, and Experience. Cambridge: Cambridge University Press.

Harper, D., \& E. Speed. (2012). Uncovering Recovery: The Resistible Rise of Recovery and Resilience. Studies in Social Justice 6(1):9-25.

Hirschkind, C. (2009). Ethical Soundscape: Cassette Sermons and Islamic Counterpublics. Columbia: University Press.

Hopper, K. (1991). Some old questions for the new cross-cultural psychiatry. Medical anthropology quarterly $5(4): 299-330$.

Hopper, K. (2004). Interrogating the meaning of culture in the WHO international studies of schizophrenia. In Schizophrenia, Culture and Subjectivity. J. Jenkins and R. Barrett, eds. Pp.62-86. Cambridge: University Press.

Hopper, K., G. Harrison, A. Janca, \& N. Sartorius (2007). Recovery from Schizophrenia: An International Perspective. New York: Oxford University Press.

Jablensky, A., N. Sartorius, G. Ernberg, M. Anker, J. Cooper, R. Day, \& A. Bertelsen (1992). Schizophrenia: Manifestations, incidence and course in different cultures. Psychological medicine 20:1-97.

Jackson, M. (2005). Existential Anthropology: Events, Exigencies, And Effects Oxford: Berghahn Books.

Jenkins, J. (1991). Anthropology, Expressed Emotion, and Schizophrenia. Ethos 19(4):387-431.

Jenkins, J. \& E. Carpenter-Song (2005). The new paradigm of recovery from schizophrenia: Cultural conundrums of improvement without cure. Culture, Medicine and Psychiatry 29:379-413.

Jenkins, J., E. Milton, E. Carpenter, J. Floersch, \& M. Sajatovic (2005). Subjective Experience of Recovery from Schizophrenia-Related Disorders and Atypical Antipsychotics. International Journal of Social Psychiatry 51:211-227.

Kleinman, A. (1987). Anthropology and psychiatry. British journal of psychiatry 151:447-454.

Kleinman, A. (1988). The illness narratives. New York: Basic books.

Lambek, M. (1988). Spirit Possession/Spirit Succession: Aspects of Social Continuity among the Malagasy Speakers in Mayotte. American Ethnologist 15(4):710-731

Lambek, M. (1989). From Disease to Discourse: Remarks on the Conceptualisation of Trance and Spirit Possession. In Altered States of Consciousness and Mental Health: A cross-cultural perspective. C. Ward, ed. Pp.36-61. Newbury Park, London: Sage Publications.

Leamy, M., V. Bird, C. Le Boutillier, \& M. Slade (2011). Conceptual framework for personal recovery in mental health. British Journal of Psychiatry 199:445-452.

Lewis, I. (1971). Ecstatic Religion: An Anthropological Study of Spirit Possession and Shamanism. Penguin: Harmondsworth

Lieberman, J., R. Drake, L. Sederer, D. Perkins, \& S. Stroup (2008). Science and Recovery in Schizophrenia. Psychiatric Services 59(5):487-496.

Masquelier, A. (2002). From Hostage to Host: Confessions of a Spirit Medium in Niger. Ethos 30(1/2): 49-76. 
Mattingly, C. (1998). Healing Dramas and Clinical Plots: The Narrative Structure of Experience. Cambridge: Cambridge University Press.

McIntosh, J. (2004). Reluctant Muslims: Embodied Hegemony and Moral Resistance in a Giriama Spirit-Possession Complex. The Journal of the Royal Anthropological Institute 10(1):91-112.

Morsy, S. (1978). Sex Roles, Power, and Illness in an Egyptian Village. American Ethnologist 5: 137-150.

Morsy, S. (1993). Gender, sickness and healing in rural Egypt: ethnography in historical context. Boulder: Westview press.

Padwick, C. (1924). Notes on the Jinn and the Ghoul in the Peasant Mind of Lower-Egypt. Bulletin of the School of Oriental Studies 3(3):421-446.

Phillips, J. (2003). Psychopathology and the Narrative Self. Philosophy, Psychiatry, and Psychology 10(4): 313-328.

Placido, B. (2001). 'It's all to do with words': An Analysis of Spirit-Possession in the Venezuelan Cult of MariaLionza. The Journal of the Royal Anthropological Institute 7(2):207-224.

Rasmussen, J.(1995). Spirit-Possession and Personhood among the Kel-Ewey Tuareg. Cambridge: University Press.

Roberts, G, \& P. Wolfson (2004). The rediscovery of recovery. Advances in Psychiatric Treatment 10:37-48.

Schrank, B. \& M. Slade (2007). Recovery in psychiatry. Psychiatric Bulletin 31:321-325

Sengers, G.(2003). Women and demons: cult healing in Islamic Egypt. Leiden: Brill.

Sharp, L. (1994). Exorcists, psychiatrists, and the problems of possession in northwest Madagascar. Social Science and Medicine 38(4):525-542

Shepherd, G., J. Boardman \& M. Slade (2008). Making Recovery a Reality. London: Sainsbury Centre.

Slade, M., M. Amering, M. Farkas, B. Hamilton, M. O'Hagan, G. Panther, R. Perkins, G. Shepherd, S. Tse, and R. Whitley. (2014). Uses and Abuses of Recovery: Implementing Recovery-Oriented Practices in Mental Health Systems. World Psychiatry 13(1):12-20.

Winkler, H. (1933/2009). Ghost Riders of Upper Egypt: A Study of Spirit-Possession. Cairo: AUC Press.

WHO (2002). Mental health global action programme. Online: http://www.who.int/mental health/media/en/265.pdf 